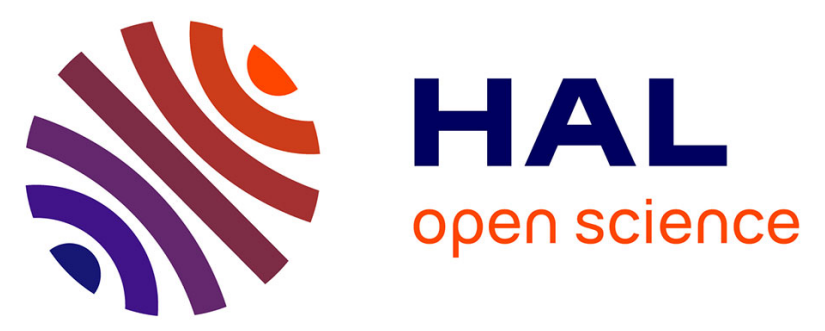

\title{
Neutron structure of type III Antifreeze Protein allows the reconstruction of AFP-ice interface
}

\author{
Eduardo Howard, Matthew Blakeley, Michael Haertlein, Isabelle \\ Petit-Hartlein, Andre Mitschler, Stuart Fisher, Alexandra Cousido-Siah, \\ Andres Salvay, Alexandre Popov, Christophe Muller-Dieckmann, et al.
}

\section{To cite this version:}

Eduardo Howard, Matthew Blakeley, Michael Haertlein, Isabelle Petit-Hartlein, Andre Mitschler, et al.. Neutron structure of type III Antifreeze Protein allows the reconstruction of AFP-ice interface. Journal of Molecular Recognition, 2011, 24 (4), pp.724. 10.1002/jmr.1130 . hal-00629934

\section{HAL Id: hal-00629934 https://hal.science/hal-00629934}

Submitted on 7 Oct 2011

HAL is a multi-disciplinary open access archive for the deposit and dissemination of scientific research documents, whether they are published or not. The documents may come from teaching and research institutions in France or abroad, or from public or private research centers.
L'archive ouverte pluridisciplinaire HAL, est destinée au dépôt et à la diffusion de documents scientifiques de niveau recherche, publiés ou non, émanant des établissements d'enseignement et de recherche français ou étrangers, des laboratoires publics ou privés. 
Journal of Molecular Recognition

WILEY

\section{Neutron structure of type III Antifreeze Protein allows the reconstruction of AFP-ice interface}

\begin{tabular}{|c|c|}
\hline Journal: & Journal of Molecular Recognition \\
\hline Manuscript ID: & JMR-10-0126.R1 \\
\hline Wiley - Manuscript type: & Research Article \\
\hline $\begin{array}{r}\text { Date Submitted by the } \\
\text { Author: }\end{array}$ & 19-Jan-2011 \\
\hline Complete List of Authors: & $\begin{array}{l}\text { Podjarny, Alberto; IGBMC, Structural Biology } \\
\text { Howard, Eduardo; IFLYSIB } \\
\text { Blakeley, Matthew; ILL } \\
\text { Haertlein, Michael; ILL, PSB } \\
\text { Petit-Hartlein, Isabelle; IBS } \\
\text { Mitschler, Andre; IGBMC, Structural Biology and Genomics } \\
\text { Fisher, Stuart; ILL } \\
\text { Cousido-Siah, Alexandra; IGBMC, Structural Biology and Genomics } \\
\text { Salvay, Andres; IFLYSIB } \\
\text { Popov, Alexandre; ESRF } \\
\text { Muller-Dieckmann, Christophe; ESRF } \\
\text { Petrova, Tatiana; IMPB }\end{array}$ \\
\hline Keywords: & neutron protein crystallography, antifreeze protein \\
\hline
\end{tabular}

\section{SCHOLARONE ${ }^{\text {M }}$ Manuscripts}




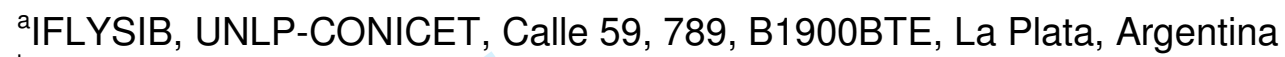

${ }^{b}$ Institut Laue-Langevin, 6 rue Jules Horowitz, 38042, Grenoble, France,

'ILL-EMBL Deuteration Laboratory, Partnership for Structural Biology, 6 rue Jules Horowitz, 38042 Grenoble, France,

'IGBMC, CNRS, INSERM, Université de Strasbourg, 1 rue Laurent Fries, Illkirch, France ${ }^{e}$ Department of Molecular Biology, Faculty of Natural Sciences, University of Salzburg, Salzburg, Austria

fUniversidad Nacional de Quilmes, Roque Sáenz Peña 352, B1876BXD Bernal, Argentina ${ }^{9}$ ESRF, 6 rue Jules Horowitz, 38043, Grenoble, France

${ }^{\mathrm{h}}$ Institute of Mathematical Problems of Biology, Russian Academy of Sciences, Pushchino, 142290 Russia

${ }^{*}$ Corresponding authors howard@iflysib.unlp.edu.ar podjarny@igbmc.fr

\section{Abstract}

Antifreeze proteins (AFPs) inhibit ice growth at sub-zero temperatures. The prototypical type-III AFPs have been extensively studied, notably by X-ray crystallography, solid-state and solution NMR, and mutagenesis, leading to the identification of a compound ice-binding surface (IBS) composed of two adjacent icebinding sections, each which binds to particular lattice planes of ice crystals, poisoning their growth. This surface, including many hydrophobic and some hydrophilic residues, has been extensively used to model the interaction of AFP with ice. Experimentally observed water molecules facing the IBS have been used in an attempt to validate these models. However, these trials have been hindered by the 
limited capability of X-ray crystallography to reliably identify all water molecules of the hydration layer. Due to the strong diffraction signal from both the oxygen and deuterium atoms, neutron diffraction provides a more effective way to determine the water molecule positions (as $D_{2} \mathrm{O}$ ). Here we report the successful structure determination at $293 \mathrm{~K}$ of fully perdeuterated type-III AFP by joint X-ray and neutron diffraction providing a very detailed description of the protein and its solvent structure. X-ray data were collected to a resolution of $1.05 \AA$, and neutron Laue data to a resolution of $1.85 \AA$ with a "radically small" crystal volume of $0.13 \mathrm{~mm}^{3}$. The identification of a tetrahedral water cluster in nuclear scattering density maps has allowed the reconstruction of the IBS-bound ice crystal primary prismatic face. Analysis of the interactions between the IBS and the bound ice crystal primary prismatic face indicates the role of the hydrophobic residues, which are found to bind inside the holes of the ice surface, thus explaining the specificity of AFPs for ice versus water.

\section{Introduction}

The so-called Antifreeze Proteins (AFPs) allow certain organisms living in cold environments to survive sub-zero temperatures. They do this by preventing ice growth and recrystallization in internal fluids through binding to ice surfaces (Davies et al., 2002; Margesin et al., 2007; Venketesh and Dayananda, 2008). This presents a unique case of molecular recognition, as AFPs need to discriminate between ice nuclei and bulk water at slightly sub-zero temperatures, and therefore, they need to recognize local structural features of ice which are not present in liquid water (Jia and Davies, 2002). 
The recognition and further binding to ice is the first stage in a two-step adsorption and growth inhibition mechanism (Raymond and DeVries, 1977). In this model, AFP molecules bind to well-defined sites on the ice surface. Ice may continue to grow between the adsorbed AFPs (which act as impurities), developing a curved front, which eventually leads to the termination of crystal growth, a phenomenon known as the Kelvin effect (Wilson, 1993; Kristiansen and Zachariassen, 2005).

The success of this protection strategy is illustrated by the wide distribution of AFPs in psychrophilic organisms, such as insects, plants, fungi and fish living in cold regions. Each of these groups contains proteins which have different origins, sequences and structures. In particular, five different types of polar fish AFPs have been described (Types I-IV and antifreeze glycoproteins) with a characteristic taxonomical distribution (DeVries, 1971; Ewart and Hew, 2002).

We have studied fish type-III AFP (HPLC-12 isoform), a prototypical globular AFP of $7 \mathrm{kDa}$ which has been the subject of a large number of experimental and computational studies, allowing the identification of a region on the protein surface as responsible for the recognition of particular lattice planes of ice (Chen and Jia, 1999; Antson et al., 2001; Siemer and McDermott, 2008; Siemer et al., 2010; Garnham et al., 2010). This compound ice-binding surface (IBS) is composed of two adjacent, nearly-flat surfaces inclined at approximately $150^{\circ}$ to each other (Figure 1a). One binds the primary prismatic plane of ice; the other, the pyramidal plane. The IBS has the peculiarity of including a large proportion of hydrophobic residues (Figure 1b). This characteristic was unexpected as it went against early proposals for the interaction of AFP with ice, which were based on a hydrogen-bonding match of AFPs to the ice surface. However, this characteristic becomes reasonable in the perspective of differentiating locally the binding to ice, from that to bulk water. For the 
case of liquid water, binding is indeed dominated by hydrogen-bonding, whereas ice presents other structural features, such as the holes in the middle of six-membered water rings, which can accommodate hydrophobic residues. As proposed by modeling studies (Yang et al., 1998) these interactions could play a main differentiation role, and would be complemented by hydrogen-bonds.

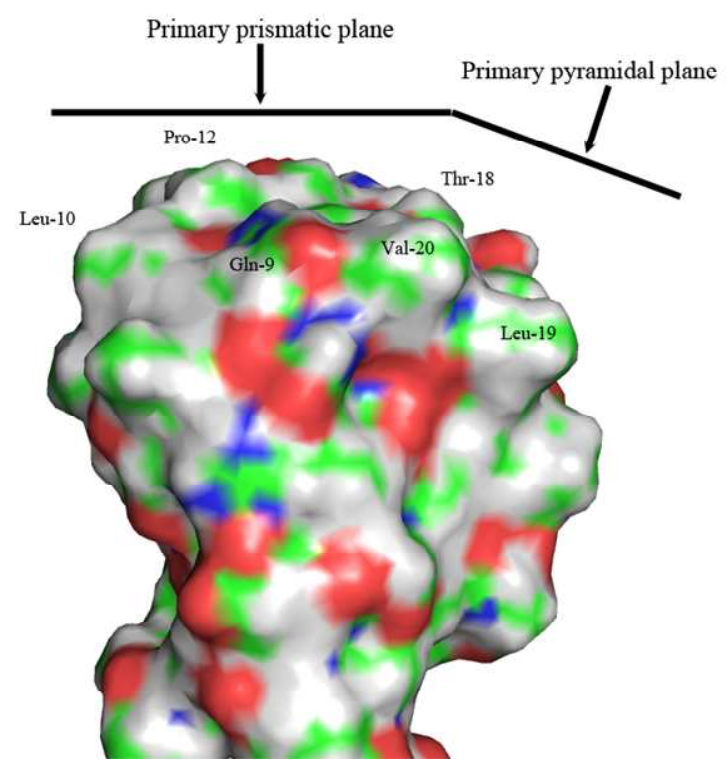

a)

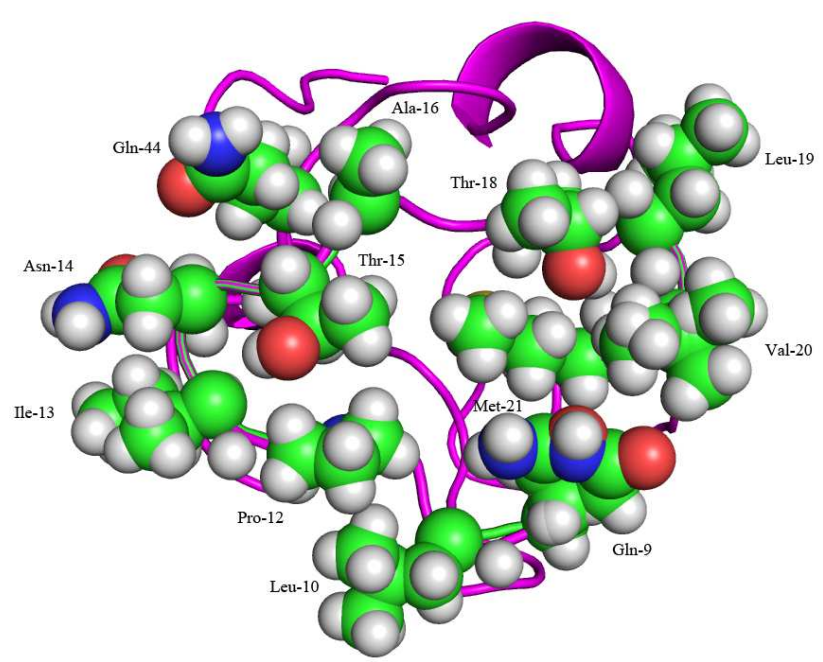

b)

Figure 1. a) Surface view of the compound ice-binding surface (IBS) of type-III AFP. The primary prismatic and pyramidal plane binding sections of AFP are indicated, along with some of the residues identified at the IBS (Gln-9, Leu-10, Pro-12, Thr-18, Leu-19 and Val-20). b) Ribbon representation of type-III AFP with all the compound ice-binding surface residues given as space-filled spheres (GIn-9, Leu-10, Pro-12, Ile-13, Asn-14, Thr-15, Ala-16, Thr-18, Leu-19, Val-20, Met-21, Gln-44). Residues are colored as follows: nitrogen = blue, oxygen $=$ red, carbon = green, and deuterium = grey .

The structure of type-III AFP protein has been extensively studied, and there are about 30 models in the Protein Data Bank (http://www.rcsb.org/pdb/) that have been solved by X-ray crystallography at various levels of resolution, including structures at different $\mathrm{pH}$ and at different temperatures (Table I, supplementary material). Several faces of the hexagonal ice structure (prismatic, basal and others) have been fitted to 
the IBS of each of these structures using modelling techniques which maximize the energy of interaction (Antson et al., 2001). In this study it is briefly mentioned that crystallographically observed waters are used as a hint to the position of ice water molecules. The result is a series of interface models, which explain the binding of AFP to several ice planes. These models are supported experimentally by macroscopic observations from etching experiments (Antson et al., 2001; Garnham et al., 2010). Nevertheless, there is no direct structural experimental evidence specifically identifying the atomic interactions of the IBS with specific water molecules in the ice planes.

In order to increase the visibility of partially disordered waters facing the IBS we have used neutron crystallographic techniques in combination with fully perdeuterated crystals of type-III AFP in heavy water $\left(D_{2} \mathrm{O}\right)$. In this way, the signal from $\mathrm{D}_{2} \mathrm{O}$ water molecules is significantly increased (about 3 times) relative to $\mathrm{H}_{2} \mathrm{O}$ water molecules, since deuterium atoms have a similar neutron scattering strength to carbon, nitrogen or oxygen atoms (note that deuterium atoms diffract $\mathrm{X}$-rays very weakly). This is particularly useful in difficult cases where the diffraction signal is close to the noise level. In addition, neutrons do not provoke any observable crystal radiation damage, and therefore allow studies without cryo-cooling of the crystals, in conditions which are close to those in-vivo.

In spite of these advantages with respect to X-ray protein crystallography, fewer than 50 structures solved by neutron diffraction techniques are deposited in the Protein Data Bank (around $1 / 1000$ of the total), mostly from partially deuterated (with only exchangeable hydrogen atoms replaced by deuterium) crystals. The reasons for this low number are that neutron sources are very few and their fluxes are relatively low, 
and therefore very large crystals (which are difficult to grow) and long data collection times (in the order of weeks) have been needed to compensate for these limitations.

Recently, the use of fully perdeuterated crystals, obtained from samples from dedicated deuteration facilities (Forsyth et al., 2001), and the improvement of data collection beam-lines, have allowed the use of much smaller crystals and therefore enlarged the field of applicability of neutron diffraction to biological problems (Blakeley, 2009). This is the case in the present work, where high quality neutron data has been obtained from a radically small crystal (volume $=0.13 \mathrm{~mm}^{3}$ ) by neutron diffraction standards.

\section{Materials and Methods}

\section{Production and characterization of perdeuterated type-III AFP (AFP}

D)

The synthetic gene of the type-III AFP corresponding to the sequence of the $1 \mathrm{HG} 7$ PDB entry (http://www.rcsb.org/pdb/explore/explore.do?structureld=1HG7) (Antson et al., 2001) was used (Salvay et al., 2007). It was over-expressed in Escherichia coli BL21(DE3) at the ILL-EMBL Deuteration Facility in Grenoble, France (Petit-Haertlein et al., 2009). The molecular weight of AFP D and its deuteration level were determined by MALDI Mass Spectrometry. Samples of concentrated native AFP diluted in trifluoroacetic acid $0.1 \%$ (Sigma) (final concentration about $10 \mathrm{mM}$ ), were mixed with an equal volume of a saturated solution of sinapinic acid (Fluka) prepared in a $50 \%(\mathrm{v} / \mathrm{v})$ solution of acetonitrile/aqueous $0.3 \%$ trifluoroacetic acid directly on the stainless steel sample plate and air-dried prior to analysis. The measured molecular weight obtained (7456 Da), when AFP D was refolded in $\mathrm{H}_{2} \mathrm{O}$ buffer, is very close to 
the theoretical value $(7452 \mathrm{Da})$, indicating that more than $99 \%$ of the 418 nonexchangeable (carbon-bound) hydrogen atoms were replaced by deuterium atoms. We conclude that AFP expressed under the conditions described above, and refolded in deuterated buffer, is fully deuterium-labeled i.e. perdeuterated.

\section{Crystallization}

The crystallization of AFP D in $\mathrm{D}_{2} \mathrm{O}$ was reported previously (Petit-Haertlein et al., 2009; Petit-Haertlein et al., 2010). All crystallization experiments were carried out by the sitting-drop vapour-diffusion method in 24-well sitting-drop Cryschem plates (Hampton Research). The particular conditions were adapted from those of AFP $\mathrm{H}$ in aqueous solution by a grid search for the optimal conditions for obtaining large crystals. The differences between AFP D and AFP $H$ crystallization conditions respectively were: (i) temperature $12^{\circ} \mathrm{C}$ versus $22^{\circ} \mathrm{C}$; (ii) $\mathrm{pH}=4.8$ ( $\mathrm{pD}=5.2$ ) versus $\mathrm{pH}=4.5$; (iii) sodium acetate concentration in the reservoir $50 \mathrm{mM}$ versus $20 \mathrm{mM}$; (iv) initial concentration of ammonium sulfate in the drop $1.5 \mathrm{M}$ versus $1.1 \mathrm{M}$.

The $50 \mu \mathrm{l}$ sitting-drop was prepared at $285 \mathrm{~K}$ using $16 \mu \mathrm{l}$ protein sample and $34 \mu \mathrm{l}$ reservoir solution and was equilibrated against $800 \mu \mathrm{l}$ reservoir solution $(2.2 \mathrm{M}$ ammonium sulfate, $9 \% \mathrm{~d}_{8}$-glycerol, $50 \mathrm{~m} M$ sodium acetate, $\mathrm{pD} 5.2$, temperature $\left.12^{\circ} \mathrm{C}\right)$. With these conditions, orthorhombic-shaped crystals appeared after 3 weeks and grew to maximum dimensions of $0.35 \times 0.55 \times 0.7 \mathrm{~mm}$, corresponding to a crystal volume of $0.13 \mathrm{~mm}^{3}$.

\section{X-ray data collection}

X-ray diffraction data of perdeuterated type-III AFP crystals were measured at the ESRF beam-line ID29 at room temperature. Special care was taken to minimize the 
radiation-induced damage when collecting data at room temperature, especially as high doses of X-ray photons are needed to measure accurately the highest possible resolution data. Three crystals of the same batch with approximate dimensions of 0.2 $\times 0.2 \times 0.6 \mathrm{~mm}$ were measured - the best of these provided X-ray diffraction data to a resolution of $1.05 \AA$ with adequate data processing statistics [see Table 1].

Table 1. X-ray data collection statistics for the AFP D crystal with volume of $0.024 \mathrm{~mm}^{3}$. Values in parentheses are for the highest resolution shell.

\begin{tabular}{|c|c|}
\hline X-ray source, beam-line & ESRF, ID29 \\
\hline Wavelength $(\AA ̊)$ & 0.65250 \\
\hline Space group & $P 2_{1} 2_{1} 2_{1}$ \\
\hline Unit-cell parameters & 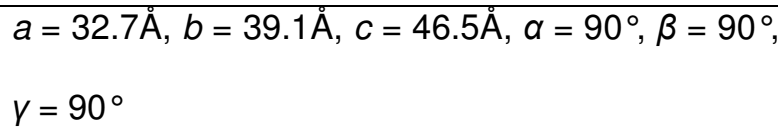 \\
\hline Resolution range $(\AA)$ & $50-1.05(1.09-1.05)$ \\
\hline No. of observations & 173588 \\
\hline No. of unique reflections & $28534(2819)$ \\
\hline Completeness (\%) & 99.7 (99.9) \\
\hline$R_{\text {merge }}^{\#}$ & $0.048(0.638)$ \\
\hline Mean $I / \sigma(I)$ & $32.5(2.66)$ \\
\hline Multiplicity & 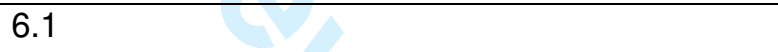 \\
\hline
\end{tabular}

${ }^{\#} R_{\text {merge }}=\Sigma_{h k l} \Sigma_{i} \mid l_{i}(h k l)-\langle l(h k l)>| / \Sigma_{h k l} \Sigma_{i} l_{i}(h k l)$, where $l(h k l)$ is the intensity of reflection $h k l, \Sigma_{h k l}$ is the sum over all reflections and $\Sigma_{i}$ is the sum over $i$ measurements of reflection $h k l$.

\section{Neutron data collection}

Neutron quasi-Laue data were collected at $293 \mathrm{~K}$ on the LADI-III beam-line (Blakeley et al., 2010) installed on cold neutron guide $\mathrm{H} 142$ at the Institut Laue-Langevin. Using the crystal of AFP D with a volume of $0.13 \mathrm{~mm}^{3}$, diffraction data were collected to $1.85 \AA$ resolution. As is typical for a Laue experiment, the crystal was held stationary 
at a different $\varphi$ setting for each exposure. Initially, 13 contiguous images $\left(\Delta \varphi=7^{\circ}\right)$ were collected using an exposure time of $24 \mathrm{~h}$ per image in order to collect the highresolution data, followed by a low-resolution pass of 18 images $\left(\Delta \varphi=5^{\circ}\right)$ using an exposure time of $2 \mathrm{~h}$ per image. Next, the crystal orientation was modified and a further 13 images were collected $\left(\Delta \varphi=7^{\circ}\right)$ using an exposure time of $6 \mathrm{~h}$ per image, followed by 18 images $\left(\Delta \varphi=5^{\circ}\right)$ using an exposure time of $2 \mathrm{~h}$ per image. Finally, the crystal orientation was modified again and a further 20 images ( $2 \mathrm{~h}$ per image, $\Delta \varphi=$ $\left.5^{\circ}\right)$ were collected, such that the complete data set comprised 82 images with an average exposure time of $6.15 \mathrm{~h}$ per image. The neutron Laue data images were processed using the Daresbury Laboratory LAUE suite program LAUEGEN, which was modified to account for the cylindrical geometry of the detector (Campbell et al., 1998). The program LSCALE (Arzt et al., 1999) was used to determine the wavelength-normalization curve using the intensities of symmetry-equivalent reflections measured at different wavelengths and to apply wavelength-normalization calculations to the observed data. The data were then scaled and merged in SCALA (Collaborative Computational Project, Number 4, 1994). Data collection statistics are summarized in Table 2. 
Table 2. Neutron quasi-Laue data collection statistics for the AFP D crystal with volume of $0.13 \mathrm{~mm}^{3}$. Values in parentheses are for the highest resolution shell.

\begin{tabular}{|c|c|}
\hline Neutron source, guide, instrument & $\begin{array}{l}\text { Institut Laue-Langevin, Cold neutron guide } \mathrm{H} 142 \text {, } \\
\text { LADI-III }\end{array}$ \\
\hline Wavelength $(\AA)$ & $3.18-4.22$ \\
\hline No. of images & 82 \\
\hline Image width & Stationary \\
\hline Setting spacing $\left({ }^{\circ}\right)$ & 5,7 \\
\hline Average exposure time (h) & 6.15 \\
\hline Space group & $P 2_{1} 2_{1} 2_{1}$ \\
\hline Unit-cell parameters & 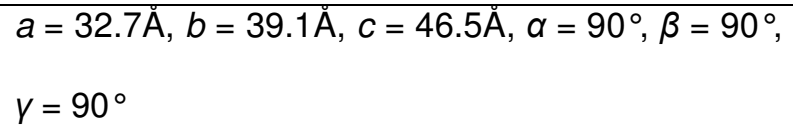 \\
\hline Resolution range $(\AA)$ & $32.74-1.85(1.95-1.85)$ \\
\hline No. of observations & $71182(3133)$ \\
\hline No. of unique reflections & $4803(544)$ \\
\hline Completeness (\%) & $89.3(71.4)$ \\
\hline$R_{\text {merge }}{ }^{\#}$ & $0.140(0.195)$ \\
\hline$R_{\text {p.i.m. }}\left(\text { all } I^{+} \text {and } I\right)^{\S}$ & $0.031(0.069)$ \\
\hline Mean $I / \sigma(I)$ & $17.5(5.5)$ \\
\hline Multiplicity & $14.8(5.8)$ \\
\hline
\end{tabular}

${ }^{\#} R_{\text {merge }}=\Sigma_{h k l} \Sigma_{i} \mid l_{i}(h k l)-\langle l(h k l)>| / \Sigma_{h k l} \Sigma_{i} l_{i}(h k l)$, where $/(h k l)$ is the intensity of reflection $h k l, \Sigma_{h k l}$ is the sum over all reflections and $\Sigma_{i}$ is the sum over $i$ measurements of reflection $h k l$.

${ }^{\S} R_{\text {p.i.m. }}=\Sigma_{h k l}[1 /(N-1)]^{1 / 2} \Sigma_{i}\left|l_{i}(h k l)-\langle l(h k l)\rangle\right| / \Sigma_{h k l} \Sigma_{i} l_{i}(h k l)$ (Weiss, 2001), where $l(h k l)$ is the intensity of reflection $h k l, \Sigma_{h k l}$ is the sum over all reflections and $\Sigma_{i}$ is the sum over $i$ measurements of reflection $h k l$. 


\section{X-ray structure determination and refinement}

The D AFP structure was initially solved by molecular replacement using the PDB entry 1UCS (Ko et al., 2003) and the program AMoRe (Navaza, 1994). The structure was initially refined in a single conformation mode against the $\mathrm{X}$-ray data alone using the program REFMAC5 (Murshudov et al., 1997 ) to an $R_{\text {work }}$ of $18.7 \%$ and an $R_{\text {free }}$ of $21.2 \%$ to $1.05 \AA ̊$ resolution.

\section{Joint $\mathrm{X}+\mathrm{N}$ refinement}

The single conformation X-ray structural model of AFP D to $1.05 \AA$ resolution determined at room-temperature was used as the starting model for the refinement using both the X-ray and neutron data in a joint refinement strategy using the phenix.refine program (Afonine et al., 2010) in PHENIX (version 1.6.2). The model was first modified by removing all water molecules, and then random atom shifts $(0.2$ $\AA ̊$ ) were applied to the coordinates. Deuterium atoms where then added to the protein model using the ReadySet! program in the PHENIX program suite. Initially rigid-body refinement was performed, followed by several cycles of maximum-likelihood-based refinement of individual coordinates, atomic displacement parameters (ADPs) and atomic occupancies (isotropic for D-atoms, anisotropic for all other atoms). Using the modeling program Coot (Emsley et al., 2010), rotamer and torsion angle adjustments were made manually throughout the model according to positive nuclear scattering density in both $\sigma_{\mathrm{A}}$-weighted $2 F_{\mathrm{o}}-F_{\mathrm{c}}$ and $F_{\mathrm{o}}-F_{\mathrm{c}}$ maps. The $\mathrm{N}$-terminal methionine residue was seen to be disordered in the nuclear scattering density maps and could not be modeled. $\mathrm{D}_{2} \mathrm{O}$ molecules were added to the model according to positive nuclear density in $\sigma_{\mathrm{A}}$-weighted $F_{\mathrm{o}}-F_{\mathrm{c}}$ maps, with manual adjustment of all $\mathrm{D}_{2} \mathrm{O}$ molecules completed using both $\sigma_{\mathrm{A}}$-weighted $2 F_{\mathrm{o}}-F_{\mathrm{c}}$ and $F_{\mathrm{o}}-F_{\mathrm{c}}$ nuclear scattering 
density maps. A total of 73 solvent molecules were included in the final round of refinement using phenix.refine; 64 of these could be modeled as full $D_{2} \mathrm{O}$ molecules, with another 9 exhibiting spherical nuclear density and hence were modeled as $\mathrm{O}$ only. The neutron $R_{\text {work }}$ and $R_{\text {free }}$ values for the final model were $16.2 \%$ and $21.6 \%$, respectively, while the X-ray $R_{\text {work }}$ and $R_{\text {free }}$ values were $15.7 \%$ and $18.2 \%$, respectively. The final refinement statistics from phenix.refine are summarized in Table 3. Molprobity (Davis et al., 2007) was used to analyze the stereochemistry of the final model (see Table 3).

Table 3. Joint X-ray and neutron refinement statistics.

\begin{tabular}{|c|c|c|}
\hline Refinement & Neutron & X-ray \\
\hline Resolution range $(\AA)$ & $29.95-1.85$ & $19.6-1.05$ \\
\hline$R_{\text {work }}(\%)$ & 16.2 & 15.7 \\
\hline$R_{\text {free }}(\%)$ & 21.6 & 18.2 \\
\hline No. of reflections & 4792 & 28514 \\
\hline \multicolumn{3}{|l|}{ Model } \\
\hline $\operatorname{RMSD}_{\text {bonds }}(\AA)$ & \multicolumn{2}{|c|}{0.012} \\
\hline $\mathrm{RMSD}_{\text {angles }}\left({ }^{\circ}\right)$ & \multicolumn{2}{|c|}{1.35} \\
\hline Atoms & \multicolumn{2}{|c|}{1290} \\
\hline Solvent molecules & \multicolumn{2}{|c|}{$73\left(64 \mathrm{D}_{2} \mathrm{O}, 9\right.$ O-only) } \\
\hline Deuterium atoms & \multicolumn{2}{|c|}{689} \\
\hline Residues with alternate conformations & \multicolumn{2}{|c|}{ Gln-9, Val-20, Glu-25, Thr-28, Asp-36, Val-45, Leu-55 } \\
\hline \multicolumn{3}{|l|}{ Ramachandran plot } \\
\hline Favoured (\%) & \multicolumn{2}{|c|}{98.6} \\
\hline Outliers (\%) & \multicolumn{2}{|c|}{0} \\
\hline Rotamer outliers (\%) & \multicolumn{2}{|c|}{0} \\
\hline Accepted regions (\%) & \multicolumn{2}{|c|}{1.4} \\
\hline
\end{tabular}




\section{Results: Description of the joint X-ray/neutron structure}

In this work, we have used joint neutron and X-ray diffraction data to obtain a very complete description of the AFP structure, including the positions of all deuterium atoms of both the protein and ordered water molecules. Examples of the high quality nuclear scattering density maps are illustrated in Figures 2 and 3, for the protein and solvent respectively.

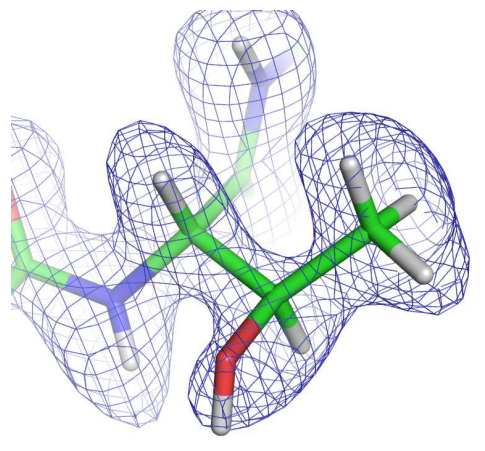

a)

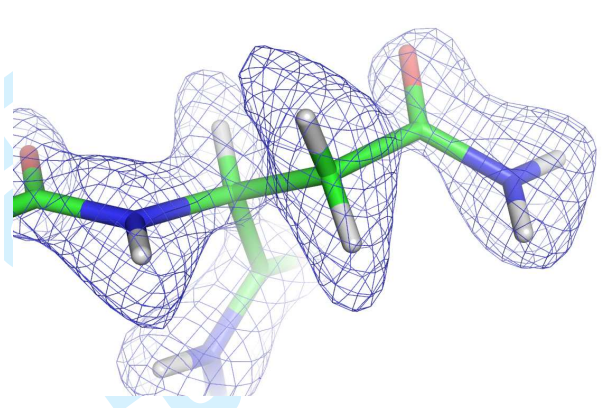

b)

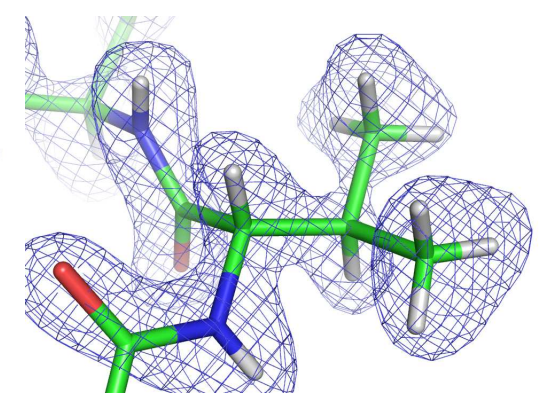

c)

Figure 2. $\quad \sigma_{A}$-weighted $2 F_{o}-F_{C}$ nuclear scattering density maps (contour level $=$ 1.6 r.m.s.) for AFP $D$ at $1.85 \AA$ resolution. a) Threonine-53. b) Asparagine-8. c) Valine-5. The orientations of the side-chains of aminoacid residues (e.g. methyl- and hydroxyl groups) are clearly seen due to the high quality of the nuclear scattering density maps obtained when using perdeuterated samples for data collection.

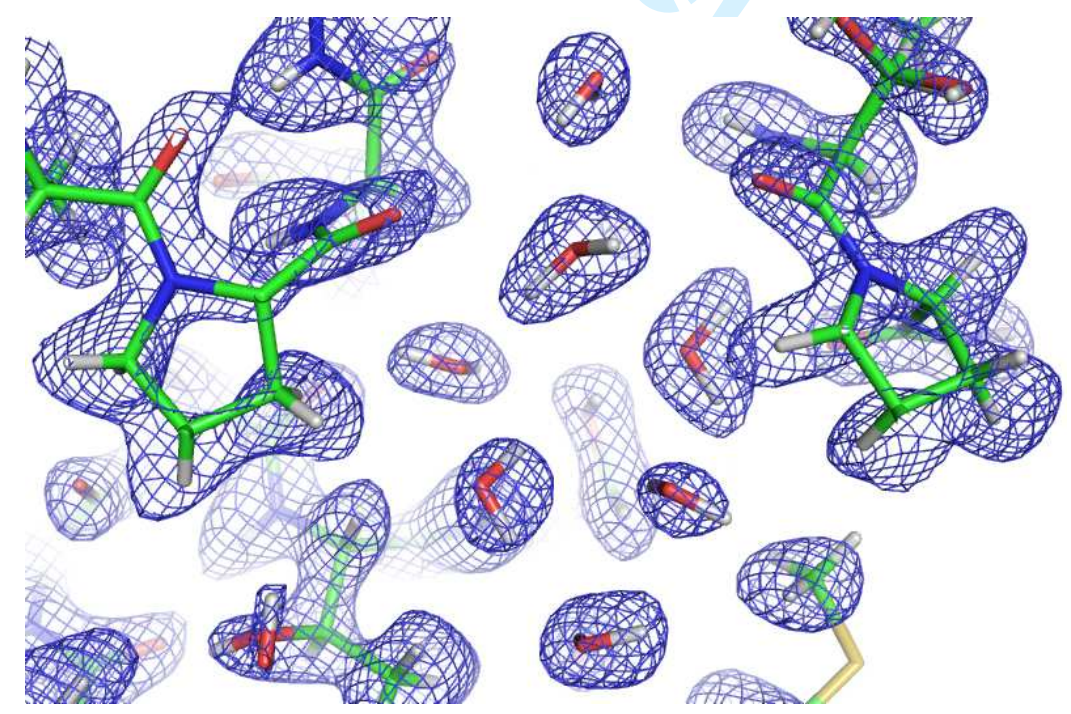

Figure 3. $\sigma_{A}$-weighted $2 F_{o}-F_{C}$ nuclear scattering density map (contour level $=$ 1.5 r.m.s.) for a water-cluster away from the IBS and located between two proline residues (Pro-29 \& Pro-57). Note that both the $O$ and $D$ atoms are clearly seen in the map, showing the water molecule positions and their orientations. 
A comparison between the present work and the previously published type-III AFPs shows that the protein structure is essentially conserved. However, the joint $\mathrm{X}+\mathrm{N}$ refinement leads to a more complete description of the hydration layer, including both ordered (64 $\mathrm{D}_{2} \mathrm{O}$ molecules) and slightly disordered waters (9 O-only), which are difficult to see with X-ray diffraction. Note that disordered water molecules do not contribute to high-resolution diffraction, and therefore this difficulty is not overcome by obtaining very high resolution X-ray data.

\section{Identification of the tetrahedral water}

From analysis of the nuclear scattering density maps for the solvent structure, we were able to identify a cluster of four water molecules bound to a pocket in the IBS (Figure 4) formed by Gln-9, Thr-18, Val-20 and Met-21. This water cluster was seen to be close to tetrahedral geometry with one of the water molecules (1004) clearly more disordered than the three others (Figure 5a). Upon close examination of the Xray maps for this disordered water, two positions (1004A and 1004B) could be modeled (Figure 5b) indicating a split water position, with one of them (1004A) being in almost perfect tetrahedral geometry. The fact that this water has a split conformation and a relatively weak signal explains why it has been overlooked by previous structure determinations. Note also that this water cluster is observed in a region accessible to the solvent, while other parts of the IBS are involved in intermolecular contacts in the crystal and therefore possible similar clusters cannot be observed as the accessible surface is blocked by neighbouring molecules. 

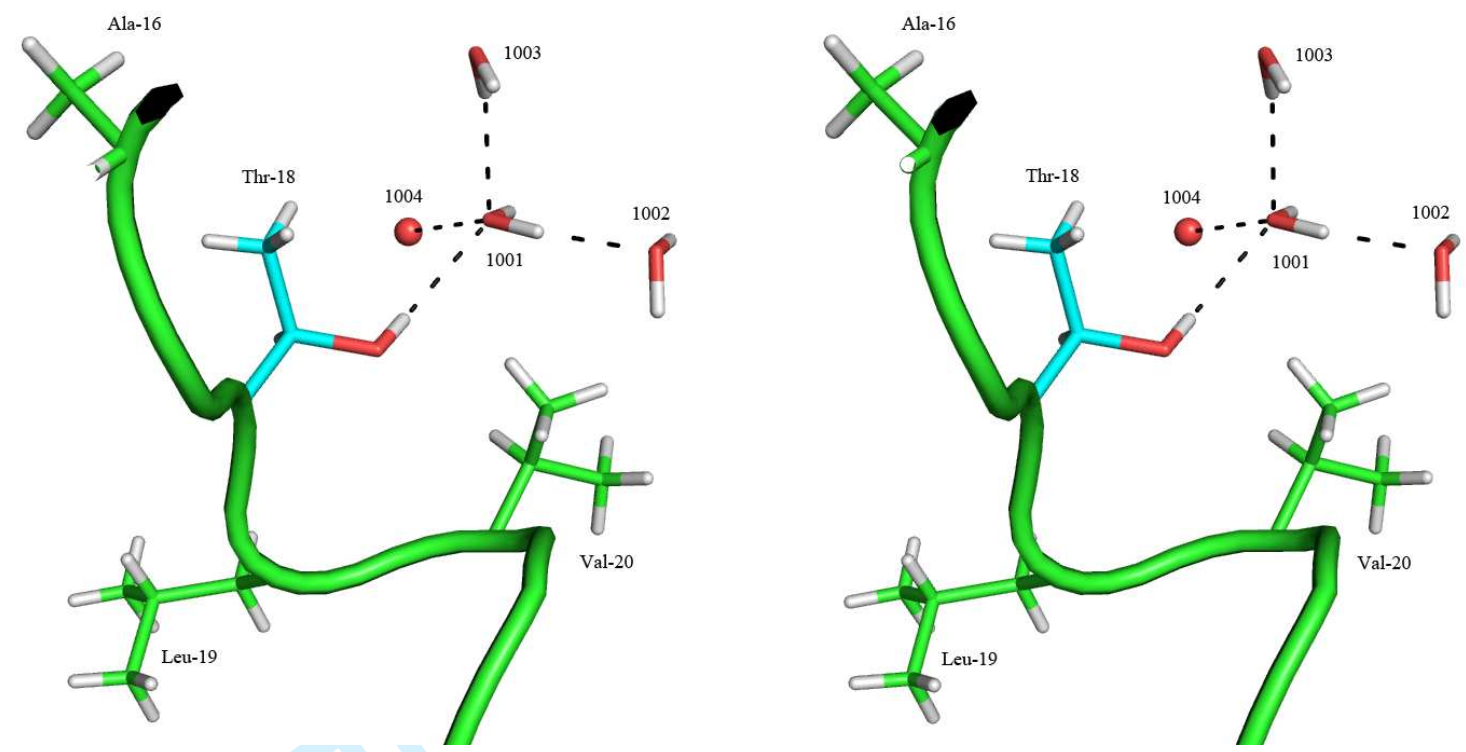

Figure 4. Stereo view of the tetrahedral water cluster bound to a pocket in the IBS. Some of the side-chains of amino-acid residues (Ala-16, Thr-18, Leu-19 and Val-20) in the vicinity of the water cluster are shown also.
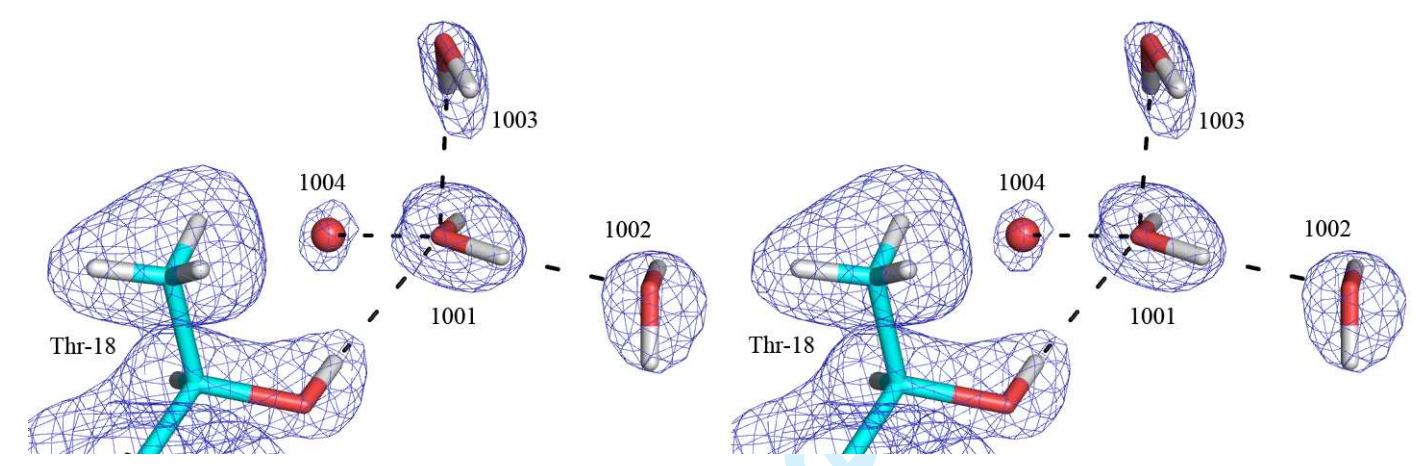

a)
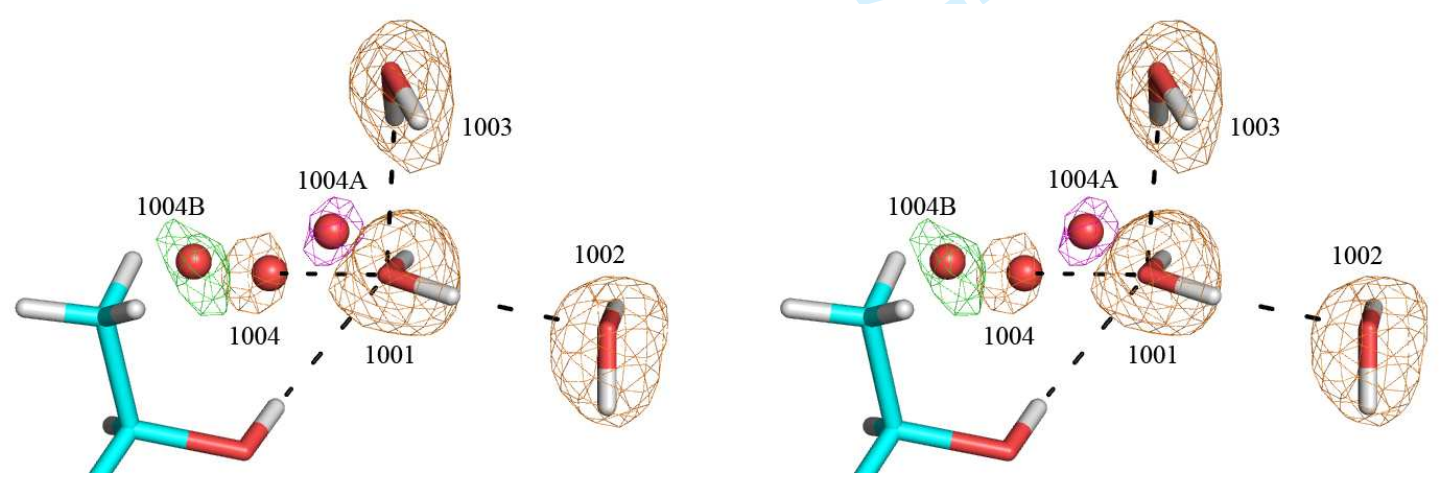

b)

Figure 5. Superposition of the tetrahedral water cluster model and density maps.

a) In blue, the $\sigma_{A}$-weighted $2 F_{o}-F_{C}$ nuclear scattering density map (contour level $=1$ r.m.s.) for the tetrahedral water cluster. Note that while there are large nuclear scattering peaks for the three water molecules 1001, 1002 and 1003, the nuclear scattering peak for water 
1004 is much weaker, indicating disorder - as such it can only be modeled as an oxygen atom.

b) In orange, the $\sigma_{A}$-weighted $F_{O}-F_{C}$ omit nuclear scattering density map (contour level $=2.6 \sigma$ ) for the tetrahedral water cluster, showing the strong signal for three of the four water molecules $(1001,1002,1003)$ and a relatively weaker signal for the disordered water 1004 . From analysis of the room temperature X-ray data for this tetrahedral water cluster, the water identified as disordered in the nuclear scattering density maps (1004) is found to be disordered in the electron density maps also. The electron density maps indicate that this water is in a split conformation, with the 2 sites (1004A and 1004B) located either side of the position identified from the nuclear scattering density maps (1004). In magenta, the $\sigma_{A}$-weighted $F_{o}-F_{c}$ electron density map (contour level $=2.6 \sigma$ ) showing the peak for the first position 1004A of the disordered water. The position of $1004 \mathrm{~A}$ is seen to be in ideal tetrahedral geometry for the water cluster. In green, the $\sigma_{\mathrm{A}}$-weighted $F_{O}$ $-F_{c}$ electron density map (contour level $=2.6 \sigma$ ) showing the peak for the second position 1004B of the disordered water.

\section{Ice Model building}

The tetrahedral water cluster was then used to fit a primary prismatic plane of ice to the protein. This was done by simple least-squares superposition using the CCP4 program LSQKAB (Kabsch, 1976; see figure 1S). Three waters of the tetrahedral cluster were then expanded to a six member water ring, which is the basic building block of the hexagonal ice structure. When doing this expansion, there are two possibilities for the water ring conformation: (1) boat or (2) chair. The boat conformation clearly placed the primary prismatic face roughly parallel to the orientation of the IBS plane and therefore was chosen as the most plausible orientation (Figure 6). The chair conformation placed the basal face roughly parallel to the IBS plane. It should be noted that the fit between a complete ice face and the IBS is not perfect, as there are short contacts between Pro-12 (which protrudes slightly from the IBS plane) and the ice faces (Figure 7). 


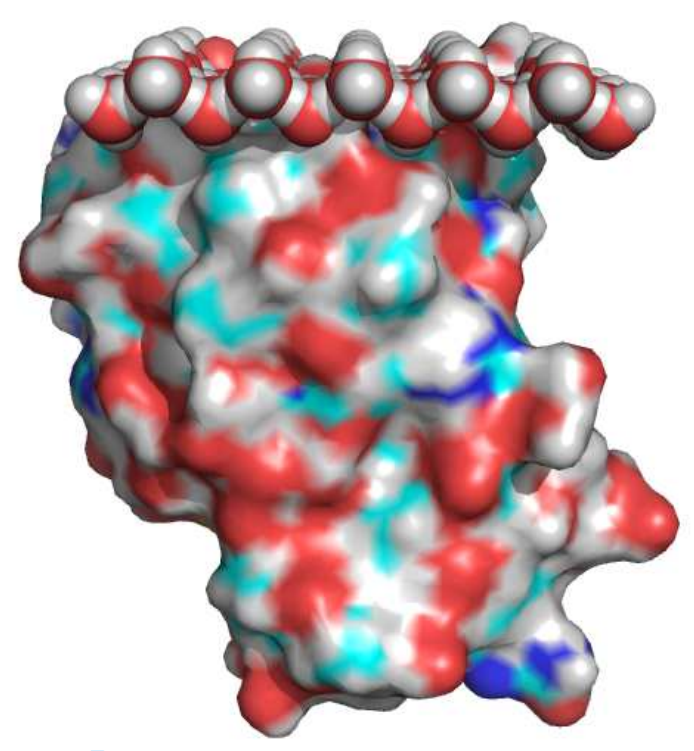

Figure 6. Primary prismatic ice face bound to the IBS in type-III AFP, built by expansion of the experimentally determined positions of the tetrahedral water cluster.

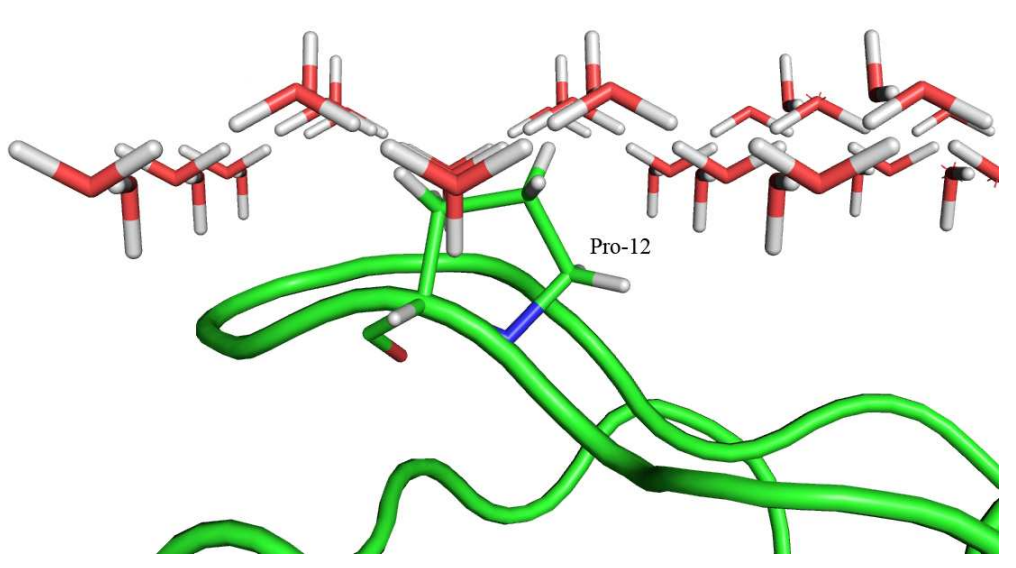

Figure 7. A close-up of the superposed prismatic plane of ice interaction with the IBS, illustrating the short contacts between Pro-12 and the ice face (other side chains have been removed for clarity).

\section{Analysis of the ice model}

From inspection of the AFP-ice interaction it could be clearly seen that the hydrophobic patches (such as the methyl groups of Thr-18, Val-20, Met-21) at the IBS face the holes in the middle of the ice water rings (Figure 8). This is in agreement 
with the NMR observation (Siemer and McDermott, 2008) that these hydrophobic residues make strong van der Waals interactions with ice, necessitating a large interaction surface that can be provided by burying these residues in the water rings. The ice waters resulting from this model show clear $\mathrm{H}$-Bond interactions with the polar IBS residues. The van der Waals interactions observed here are similar to those in water clathrate-protein interactions, such as those identified in crambin (Teeter et al., 2001), however, in the AFP-ice case the van der Waals interactions are made with the six-membered rings of the ice structure, while in water clathrateprotein interactions the van der Waals interactions are more commonly observed for pentagonal arrangements of water molecules.

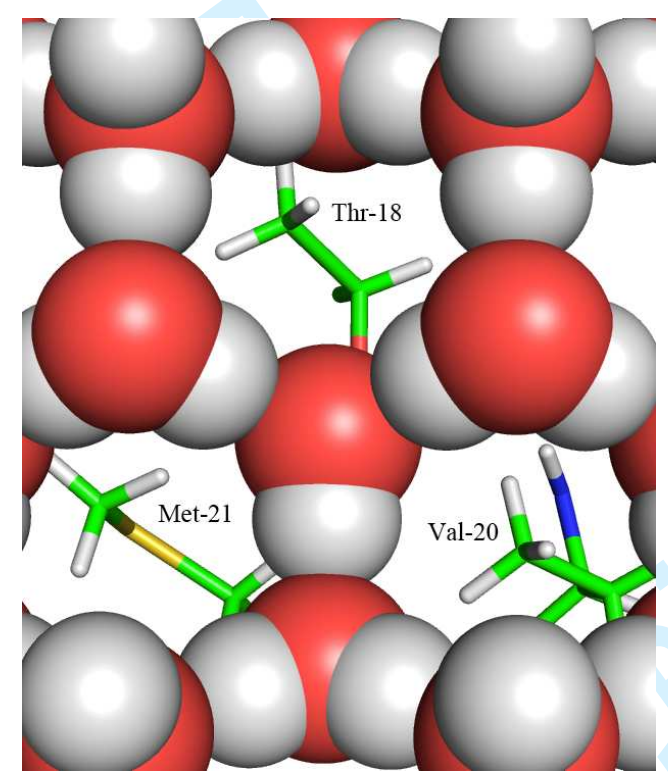

Figure 8. Detail of the interface showing the methyl groups of the hydrophobic residues Thr-18, Val-20 and Met-21 are placed facing the holes in the ice structure.

\section{Discussion}

We have determined the structure of type-III AFP and its hydration layer using joint neutron and X-ray diffraction data to obtain a maximum signal for the water molecules. Within the solvent structure we have been able to identify a water cluster with a tetrahedral geometry, typical of ice crystals. We have made the assumption 
that this water cluster corresponds to the binding of type-III AFP to ice nuclei, and we have built a model of the interface of the IBS with the primary prismatic face of ice by extending this tetrahedral ice water cluster and its environment. This resulted in a model which explains the importance of the hydrophobic patches at the IBS, as they are placed facing the holes in the ice structure in the middle of the six-membered water rings and therefore can make strong van der Waals contacts with ice.

It should be noted that one of the waters in the tetrahedral cluster is more disordered, which has probably prevented the previous identification of this tetrahedral arrangement, and that some of the IBS residues, notably Pro-12, disrupt the prismatic face continuity. On the other hand, the position of Pro-12 could favor the binding of the pyramidal face as proposed by Garnham et al., 2010 (Fig 1a). A key question is the reliability of the positioning of the tetrahedral water (1004A) facing the IBS. To verify this hypothesis, we analyzed all related structures of type-III AFP's deposited crystallographically determined and currently in the PDB (18 in total, see Table 1S). The positions of the water molecules described in this paper were compared with those observed in these structures.

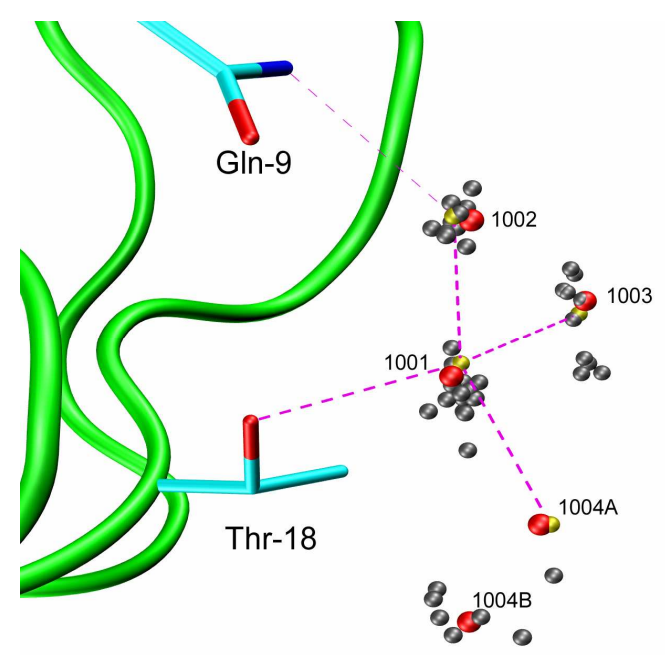

Figure 9. Comparison of tetrahedral waters with those observed in similar structures deposited in the PDB. The waters observed in this paper are 
shown as red spheres, the superposed tetrahedral ice cluster is shown as yellow spheres (see figure 1S, supplementary material), and the waters from related PDB structures are shown as grey spheres.

The positions of the water molecules described in this paper were compared with those observed in similar protein structures deposited in the PDB (Figure 9, and figures $2 S$ and $3 S$ in supplementary material). Note that PDB observed water molecules which make direct protein contacts are well represented and tightly clustered around the tetrahedral positions (1001 and 1002). On the other hand, those corresponding to water 1003 are more disperse. The fourth position (1004) is the least represented and most disperse, agreeing with the double conformation that we observe. Of the two positions, 1004A and 1004B, the one with higher occupation (1004B) is the most represented in the PDB.

\section{Conclusions}

The main structural question posed by the AFP biological function is how the protein binds preferentially to ice than to water. Type-III AFP is highly soluble and does not aggregate even at high concentrations (Salvay et al., 2010), so in solution it is surrounded by liquid water. On the other hand, it has a unique IBS surface, which in the presence of ice nuclei recognizes the structural features which do not exist in liquid water. Clear examples of such unique features are the holes in the centre of the water rings of ice.

Our proposition is that the IBS face of type-III AFP uses these holes to specifically recognize ice against cold but liquid water, which has a short-range order similar to ice but in which the holes in the middle of the six-membered water rings can be filled. Note that this feature directly follows from the fitting of the experimentally determined 
tetrahedral water cluster, which has been reliably determined by the joint $\mathrm{X}+\mathrm{N}$ structure determination at room temperature.

This work highlights the importance of neutron diffraction to reliably identify hydration features in macromolecules, in particular those slightly disordered, based on its special property of the strong neutron diffraction signal of deuterium atoms. It should lead the way to further studies of this type, especially using the newly available spallation neutron sources and the methodological developments around them.

\section{Acknowledgments}

This work has benefitted from the activities of the DLAB consortium funded by the EU under contracts HPRI-2001-50065 and RII3-CT-2003-505925, and from UK EPSRCfunded activity within the ILL-EMBL Deuteration Laboratory under grants GR/R99393/01 and EP/C015452/1. This work was supported by the Human Frontiers Science Program grant RGP0021/2006-C, the Centre National de la Recherche Scientifique (CNRS), the Institut National de la Santé et de la Recherche Médicale, the Hôpital Universitaire de Strasbourg (H.U.S), the Université de Strasbourg, the Universidad de La Plata and the CONICET (PIP 112-200801-03247). EIH is a member of the career of Scientific Investigator of CONICET (Argentina).

\section{References}

Afonine PV, Mustyakimov M, Grosse-Kunstleve RW, Moriarty NW, Langan P, Adams PD. 2010. Joint X-ray and neutron refinement with phenix.refine. Acta Cryst. D66(Pt 11): $1153-63$.

\section{DOI:10.1107/S0907444910026582}


Antson AA, Smith DJ, Roper DI, Lewis S, Caves LSD, Verma CS, Buckley SL, Lillford PJ, Hubbard RE. 2001. Understanding the mechanism of ice binding by type-III antifreeze proteins. J. Mol. Biol. 305: 875-889.

DOI:10.1006/jmbi.2000.4336.

Arzt S, Campbell JW, Harding MM, Hao Q, Helliwell JR. 1999. LSCALE - the new normalization, scaling and absorption correction program in the Daresbury Laue software suite. J. Appl. Cryst. 32: 554-562.

DOI:10.1107/S0021889898015350

Blakeley MP. 2009. Neutron macromolecular crystallography. Crystallogr. Rev. 15: 157-218.

DOI:10.1080/08893110902965003

Blakeley MP, Teixeira SC, Petit-Haertlein I, Hazemann I, Mitschler A, Haertlein M, Howard E, Podjarny AD. 2010. Neutron macromolecular crystallography with LADIIII. Acta Cryst. D66(Pt 11):1198-205.

DOI:10.1107/S0907444910019797

Campbell JW, Hao Q, Harding MM, Nguti ND, Wilkinson C. 1998. LAUEGEN version 6.0 and INTLDM. J. Appl. Cryst. 31: 496-502.

DOI:10.1107/S0021889897016683

Chen G, Jia Z. 1999. Ice-binding surface of fish type-III antifreeze. Biophys J. 77: 1602-1608.

DOI:10.1016/S0006-3495(99)77008-6

Collaborative Computational Project, Number 4. 1994. The CCP4 suite: programs for protein crystallography. Acta Cryst., D50: 760-763.

DOI:10.1107/S0907444994003112

Davies PL, Hew CL. 1990. Biochemistry of fish antifreeze proteins. FASEB J. 4: 2460-2468.

PMID: 2185972 
Davies PL, Baardsnes J, Kuiper MJ, Walker VK. 2002. Structure and function of antifreeze proteins. Philos. Trans. R. Soc. Lond. B Biol. Sci. 357: 927-935.

DOI:10.1098/rstb.2002.1081

Davis IW, Leaver-Fay A, Chen VB, Block JN, Kapral GJ, Wang X, Murray LW, Arendall WB, Snoeyink J, Richardson JS, Richardson DC. 2007. MolProbity: all-atom contacts and structure validation for proteins and nucleic acids. Nucleic Acids Res. 35: W375-W383.

DOI:10.1093/nar/gkm216

DeLano WL. 2008. The PyMOL molecular graphics system. DeLano Scientific LLC, Palo Alto, CA, USA. http://www.pymol.org.

DeVries AL 1971. Glycoproteins as biological antifreeze agents in Antarctic fishes. Science 172: 1152-1155.

DOI:10.1126/science.172.3988.1152

Emsley P, Lohkamp B, Scott WG, Cowtan K. (2010). Features and development of Coot. Acta Cryst. D66(Pt 4):486-501.

DOI:10.1107/S0907444910007493

Ewart KV, Hew CL. 2002. Fish antifreeze proteins. World Scientific: London ISBN: 9789810248994

Forsyth VT, Myles DAA, Timmins PA, Haertlein M. 2001. Possibilities for the Exploitation of Biological Deuteration in Neutron Scattering. In Opportunities for Neutron Scattering in the 3rd Millennium, Dianoux J (Ed) Grenoble: Institut LaueLangevin; 47-54.

Garnham CP, Natarajan A, Middleton AJ, Kuiper MJ, Braslavsky I, Davies PL. 2010. Compound ice-binding site of an antifreeze protein revealed by mutagenesis and fluorescent tagging. Biochemistry. 49: 9063-9071.

DOI:10.1021/bi100516e 
Jia Z, Davies PL. 2002. Antifreeze proteins: an unusual receptor-ligand interaction. Trends Biochem. Sci. 27: 101-106.

DOI:10.1016/S0968-0004(01)02028-X.

Kabsch W. 1976. A solution for the best rotation to relate two sets of vectors. Acta. Cryst. A32: 922-923.

DOI:10.1107/S0567739476001873

Kristiansen E, Zachariassen KE. 2005. The mechanism by which fish antifreeze proteins cause thermal hysteresis. Cryobiology 51: 262-280.

DOI:10.1016/j.cryobiol.2005.07.007

Ko T-P, Robinson H, Gao Y-G, Cheng C-HC, DeVries AL, Wang AH-J. 2003. The Refined Crystal Structure of an Eel Pout Type-III Antifreeze Protein RD1 at 0.62- $\AA$ Resolution Reveals Structural Microheterogeneity of Protein and Solvation. Biophys. J. 84: 1228-1237

DOI:10.1016/S0006-3495(03)74938-8

Margesin R, Neuner G, Storey KB. 2007. Cold-loving microbes, plants, and animals fundamental and applied aspects. Naturwissenschaften 94: 77-99.

DOI:10.1007/s00114-006-0162-6

Murshudov GN, Vagin AA, Dodson EJ. 1997. Refinement of Macromolecular Structures by the Maximum-Likelihood Method. Acta Cryst. D53: 240-255.

DOI:10.1107/S0907444996012255

Navaza J. 1994. AMoRe: an automated package for molecular replacement. Acta Cryst. A50: 157-163.

DOI:10.1107/S0108767393007597

Petit-Haertlein I, Blakeley MP, Howard E, Hazemann I, Mitschler A, Haertlein M, Podjarny A. 2009. Perdeuteration, purification, crystallization and preliminary neutron diffraction of an ocean pout type-III antifreeze protein. Acta Cryst. F65: 406-409. DOI:10.1107/S1744309109008574 
Petit-Haertlein I, Blakeley MP, Howard E, Hazemann I, Mitschler A, Podjarny A, Haertlein M. 2010. Incorporation of methyl-protonated valine and leucine residues into deuterated ocean pout type-III antifreeze protein: expression, crystallization and preliminary neutron diffraction studies. Acta Cryst. F66: 665-669.

DOI:10.1107/S1744309110012352

Raymond JA, DeVries AL. 1977. Adsorption inhibition as a mechanism of freezing resistance in polar fishes. Proc. Natl. Acad. Sci. USA. 74: 2589-2593.

PMID: 267952

Salvay AG, Santos J, Howard El. 2007. Electro-optical properties characterization of Fish Type-III Antifreeze Protein. J. Biol. Phys. 33: 389-398.

DOI:10.1007/s10867-008-9080-5

Salvay AG, Gabel F, Pucci B, Santos J, Howard El, Ebel C. 2010. Structure and interactions of fish type-III antifreeze protein in solution. Biophys. J. 99: 609-618. DOI:10.1016/i.bpj.2010.04.030.

Siemer AB, McDermott AE. 2008. Solid-State NMR on a Type-III Antifreeze Protein in the Presence of Ice. J. Am. Chem. Soc. 130: 17394-17399.

DOI:10.1021/ja8047893

Siemer AB, Huang K-Y, McDermott AE. 2010. Protein-ice interaction of an antifreeze protein observed with solid-state NMR. Proc. Natl. Acad. Sci. USA. 107: 1758017585.

DOI: $10.1073 /$ pnas.1009369107

Teeter MM, Yamano A, Stec B, Mohanty U. 2001. On the nature of a glassy state of matter in a hydrated protein: Relation to protein function. Proc. Natl. Acad. Sci. USA. 98(20):11242-11247.

DOI:10.1073/pnas.201404398

Venketesh S, Dayananda C. 2008. Properties, potentials, and prospects of antifreeze proteins. Crit. Rev. Biotechnol. 28: 57-82. 


\section{DOI:10.1080/07388550801891152}

Weiss MS. 2001. Global indicators of X-ray data quality. J. Appl. Cryst. 34: 130-135. DOI:10.1107/S0021889800018227

Wilson PW. 1993. Explaining thermal hysteresis by the Kelvin effect. Cryo-Letters 14: 31-36.

Yang DSC, Hon W-C, Bubanko S, Xue Y, Seetharaman J, Hew CL, Sicheri F. 1998. Identification of the ice-binding surface on a type-III antifreeze protein with a "flatness function" algorithm. Biophys J. 74: 2142-2151.

DOI:10.1016/S0006-3495(98)77923-8 